\title{
Mathematics pre-service teacher's metacognitive failure in mathematics online learning
}

\author{
Alifiani $^{\text {a, } * \text {, Surya Sari Faradiba }}{ }^{\text {b }}$ \\ Pendidikan Matematika, Universitas Islam Malang \\ J1. MT Haryono 193 Malang, 65144, Indonesia \\ E-mail: a alifiani@ unisma.ac.id, ${ }^{\mathrm{b}}$ suryasarifaradiba@unisma.ac.id \\ * Corresponding Author
}

\begin{tabular}{l} 
ARTICLE INFO \\
\hline Article history \\
Received: 23 Aug 2021 \\
Revised: 24 Nov 2021 \\
Accepted: 29 Nov 2021 \\
Keywords \\
Cognitive style, field \\
dependence, field \\
independence, metacognitive \\
failure, problem-solving
\end{tabular}

Scan me:

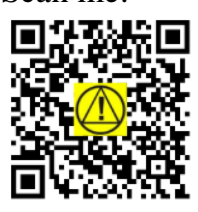

\section{ABSTRACT}

This study aims to reveal the metacognitive failures experienced by mathematics pre-service teachers based on their mistakes when solving problems in online learning during the pandemic era. This case study involved 29 participants who attended the mathematical problem test and cognitive style test, the two participants were categorized based on their cognitive style: Field Dependence (FD) and Field Independence (FI). The instrument used was a mathematical problem test to collect data on metacognitive that adapted from Stewart and a cognitive styles test to categorize the cognitive style that adapted from the Group Embedded Figures Test (GEFT). An interview was conducted to determine the nature of mathematical error based on metacognitive failure. The description of data analysis and interpretation of the meaning of the findings applied the text analysis. The results showed the different metacognitive failures of the two participants. The metacognitive failure of FI student was categorized as metacognitive blindness and the FD student was categorized as metacognitive stagnation, a new condition of metacognitive failure that was found in this study.

This is an open access article under the CC-BY-SA license.

How to Cite: Alifiani, A., \& Faradiba, S. S. (2021). Mathematics pre-service teacher's metacognitive failure in mathematics online learning. Jurnal Riset Pendidikan Matematika, 8(2), 179-190. https://dx.doi.org/10.21831/jrpm.v8i2.43366

\section{INTRODUCTION}

The COVID-19 has widespread and made a quick-growing and wellbeing emergency with exceptional impacts, especially in education. As a result, numerous nations instructed their citizens to remain at home, dodge exceptionally near physical contact, and take social or physical distance (Rahiem, 2021). Consequently, education and learning in most countries are regulated in online learning (Zheng, Khan, \& Hussain, 2020). However, students must watch out for their motivation, excitement, behavior, understanding, and technology literate during online learning. In case of students are not well literate in technology or do not feel a sense of cognitive and social engagement, there will be adverse effects on the students' learning outcome. When technology is utilized viably, students and teachers should engage and collaborate well (Patricia Aguilera-Hermida, 2020). Thus, teachers should organize the learning strategies to keep the students engaged as well (Hidayah, Sa'dijah, Subanji, \& Sudirman, 2021).

Further, Hidayah et al. (2021) revealed that in online learning, student engagement is classified into three dimensions: behavioral, emotional, and cognitive engagement. Behavioral engagement refers to taking after the rules and follow to classroom standards or concerns associated with learning and scholastic errands and incorporates behaviors such as exertion, determination, concentration, consideration, and contributing to class discussions as well as the nonappearance of troublesome behaviors such as skipping online classes and getting in inconvenience. Emotional engagement refers to students' emotional response within the classroom, counting intrigued, boredom, bliss, pity, and 
anxiety. Meanwhile, Cognitive engagement can be interpreted as the integration and utilization of students' thinking and strategies in their learning (Richardson \& Newby, 2006).

In addition, cognitive engagement would most likely indicate the student's individual learning experiences and their self-thinking ability. Cognitive engagement is characterized as a student's level of effort in learning; it incorporates students be mindful and intentional within the approach to school errands and be willing to apply the exertion fundamental to comprehend complex thoughts (Hidayah et al., 2021). This cognitive engagement is rising currently and leads to students' investment in learning, having hard effort to face challenges or problems, and utilizing more and depth self-learning strategies. Studies that clarify cognitive engagement in online learning are abundant since cognitive engagement could be a prerequisite for meaningful learning (Shukor, Tasir, Van der Meijden, \& Harun, 2014). Studies have also shown that cognitively engaged students can form new knowledge and reach a more profound understanding of online learning. Besides, cognitive engagement is an indicator of students' learning outcomes. In online learning, cognitive engagement can be evaluated by observing students' behavior in written assignments (Shukor et al., 2014).

Cognitive engagement plays an essential role in the problem-solving process and has strict influence on learning mathematics ( $\mathrm{Li}$, Lajoie, Zheng, $\mathrm{Wu}, \&$ Cheng, 2021). This problem-solving ability is the primary goal of learning mathematics, and realizing this goal becomes the teacher's attention by considering a wide range of factors and strategies (Lester, 2013). Mastering problemsolving skills, students could apply their mathematical abilities in better approaches; they create a more profound understanding of mathematical concepts and feel the involvement of being a mathematician through solving problems (Son, Darhim, \& Fatimah, 2020). Thus, there is a close and heuristic interaction between mathematical concepts and the processes utilized to solve those problems which are possessed by students who have good cognitive engagement.

As Li et al. (2021) consider the connection between cognitive engagement in solving a problem, Hidayah et al. (2021) suggest that self-regulated learning components are considered particularly relevant to student cognitive engagement as both of their research is concerned about the students' process and performance in solving the mathematical problems. According to Vula, Avdyli, Berisha, Saqipi, \& Elezi (2017), self-regulation is the capacity to control and direct students' thought-forms in accomplishing objectives or the targeted outcome. In addition, self-regulation leads to the students' ways to identify the problems and stimulate them further to get issues, screen or assess problems, and accomplish objectives or discover what comes about. Consequently, self-regulated students, given with Higher Order Thinking Skill (HOTS) problems, can think in systematic ways, consider the variables that influence learning results, think around how, when, where, and why they ought to utilize specific strategies or thought forms, and continuously prepare and think the following steps for the whole processes in solving those problems. These procedural competencies are under the point of and so-called metacognitive (Wilson \& Conyers, 2016). This metacognitive can make students think "right on the track" to progress in problem-solving (Nizlel, Subanji, Toto, Susiswo, Akbar, \& Swasono, 2016).

Faradiba, Sa'dijah, Parta, \& Rahardjo (2019) suggested that problem-solving is one form of high-level thinking closely related to metacognition. Problem-solving instruction is likely to be most successful when given in a systematically organized way beneath the heading of the teacher, considering students' metacognitive process as well. Problem-solving instruction that emphasizes the improvement of metacognitive abilities ought to include the teacher in three distinctive, but related, parts: (a) as an outside screen, (b) as a facilitator of students' metacognitive awareness, and (c) as a role model of a metacognitively capable problem solver (Lester, 2013). As Shekhar \& Rahnev (2021) stated, students have the metacognitive ability to assess the exactness of their choices through correct evaluations in solving problems. Thus, metacognitive ability is reflected by student evaluation ability in considering performance goals specifically in solving mathematical problems. Magiera \& Zawojewski (2011) classify metacognitive into three components, namely 1) metacognitive awareness, 2) metacognitive regulation, and 3) metacognitive evaluation. According to them, metacognitive awareness is an individual's awareness to think about his strategy that can be used to complete a task. Metacognitive evaluation is an individual's awareness of the limitations of the knowledge, the limitations of the strategy determined, and the quality of the results. Metacognitive regulation is the awareness to reflect what has been thought beforehand to make plans and determine goals. 
Metacognition comprises monitoring and control (Palmer, David, \& Fleming, 2014). Generally, a student has excellent metacognitive monitoring if their subjective evaluations could track their objective behavior on a trial-by-trial premise. For illustration, a metacognitively efficient student will report high confidence when they are objectively correct and low confidence when they are incorrect. In opposite, a student who has poor metacognitive efficiency or metacognitive inefficiency is not aware of those procedural competences of solving problems as shown by subjective reports that are disconnected to errand performance. Metacognitive inefficiency can be depicted as a case where students' metacognitive evaluations of certainty are less instructive and informative on the possible following steps in solving the problems (Shekhar \& Rahnev, 2021). Numerous thinks have investigated the characteristic of this inefficiency. For one case, noteworthy progress has been made in revealing the neural relates of metacognitive inefficiency and understanding whether there are consistent individual contrasts in metacognitive inefficiency. Metacognitive inefficiency can happen when certainty is impacted by an arbitrary distraction that does not influence the perceptual choice. These distraction sources can influence either the flag utilized for certainty or the certainty computation itself. Its presence leads to irrational expectations that have as of late been experimentally approved.

Metacognitive strategies can offer assistance to students by investigating the case information, planning solutions, monitoring the process of thinking, and evaluating the process that leads to solving problems (Murni, Sabandar, Kusumah, \& Kartasamita, 2013). Metacognitive strategies are vital for students in mathematical problem-solving; furthermore, students need to equip themselves with various knowledge and experience in problem-solving, which involves higher-order thinking skills (Abdullah, Mokhtar, Halim, Ali, Tahir, \& Kohar, 2017). This implies that problem-solving is not always easy for every student; students may have difficulties in solving a problem which probably caused them to make various errors. The variety of students' mathematical errors has contributed to the formation of many theories about the nature of mathematical errors, their interpretation, and their remediation (Gagatsis \& Kyriakides, 2000). The nature of mathematical errors can be categorized into mathematical error, logical error, strategic error, and psychological error (Luo, 2013). A mathematical error can be described as the confusion of concept and characteristics, negligence of the condition of formulas, and theorem. Logical errors include a false argument, disorganized concept, improper classification, unclear argument, and inequivalent transform. Meanwhile, strategic errors occur when students cannot find distinctive patterns, have lack integral concepts, cannot reflect their thinking process and transform the problem. Psychological errors are the efficiency of mentality, improper mental state (including metacognitive).

The metacognitive process cannot continuously go well as the information already possessed cannot be utilized ideally. Goos (2002) recognizes three sorts of metacognitive failures shown by problem solvers as a response to the red flag, specifically metacognitive blindness, vandalism, and mirage. Further, Goos (2002) distinguishes three red flag circumstances related to problem-solving such as lack of progress, error detection, and anomalous or bizarre results. In addition to Goos (2002), red flag circumstances are recognized from routine monitoring behaviors such as evaluation of information, approach, and results. Red flags help students to have a more controlled observation that could trigger them to become mindful of certain troubles and keep the problem-solving process on the proper track. Metacognitive red flags can occur at primary conditions where the problem-solvers got to make a vital decision that impacts the success or failure of their endeavors. Red flags also demonstrate the need for pausing for reflection, backtracking, and re-doing the problem in another way.

However, the presence or absence of subsequent metacognitive regulatory behavior as a reaction to the red flag situation also plays an essential role in taking over the problem-solving situation. Goos (2002) identified three types of metacognitive failures displayed by problem-solvers in response to red flags. These are described by the metaphors of "blindness," "vandalism," and "mirage." Metacognitive blindness occurs when a problem solver does not notice that she or he fails to solve the problem and continues with a wrong approach. Metacognitive vandalism comes into play when problem-solvers decide to take destructive action to deal with a deadlock situation such as changing the problem's conditions to suit the problem solver. Metacognitive mirage occurs when problem-solvers mistakenly change the course of actions upon the perception of difficulties, which do not exist.

Metacognitive leads to a unique individual thinking ability which is different between individuals, and essential in each individual's thinking process. So, it can be said that each individual has a cognitive style that is different from one another (Amin \& Sukestiyarno, 2015) as Ling \& Salvendy 
(2009) stated that every student has a unique cognitive style that different from each other. Cognitive style refers to an individual's habitual way of perceiving, remembering, thinking, problem-solving, organizing and representing information (Ling \& Salvendy, 2009). Cognitive style can be defined as a thought process, perspective, or strategy commonly used to obtain and process information (Kozhevnikov et al., 2014). Although each individual has a similar mindset, perspective, and approach, each processes information in their ways depending on their cognitive abilities (Riding \& Rayner, 2020). Differences in individual cognitive styles can also influence how individuals respond to environmental conditions (Oh \& Lim, 2005).

One valuable variable that can impact problem-solving is cognitive style (Mefoh, Nwoke, Chukwuorji, \& Chijioke, 2017). Cognitive style alludes to the preferred way students handle information of the distinctive ways they think and learn. Cognitive style is 'a resolute characteristic and steady approach to organizing and handling information' or a 'fairly settled characteristics of a person who is inactive and generally in-built highlights of the individual'. Research in cognitive psychology shows that individuals show noteworthy contrasts within the cognitive processing styles they embrace in problem-solving and other decision-making tasks. Students embrace diverse perceptual approaches in understanding problems; a few of the best-known approaches incorporate field dependenceindependence, convergent-divergent, visualize-verbalizer, and the adaptation-innovation dimensions.

Mefoh et al. (2017) expressed that the field dependence-independence cognitive style is the foremost well-known cognitive style. Oh \& Lim (2005) stated that each individual has different cognitive styles and can be categorized into two large groups, namely fields independent (FI) and fielddependent (FD). Concurring to the field-dependent theory, individuals who have the field-independent cognitive style tend to take note of detail and have more noteworthy expository and separating capacity than field-dependent individuals - that is, individuals who show up to see occasions all-inclusive without considering the subtle elements. A field-independent individual tends to verbalize figures as discrete from their backgrounds and effortlessly separates objects from inserting substance, but a field-dependent individual tends to involvement occasions universally in an undifferentiated style. FI tends to look at the environment analytically, classifying things based on specific criteria, while individuals with FD tend to understand things in a relatively global way, easily influenced by the environment or context (Oh \& Lim, 2005). Riding \& Rayner (2020) supported this argument that individuals with FI are always involving analysis, paying attention to details, trying to master tasks and other focused activities. In contrast to FD, who are more social, empathetic, and responsive, have better communication skills. Therefore, we can conclude that the difference between FI students and FD students in solving problems, FI students tend to be independent and confident, while FD students tend to rely on external influences (Son et al., 2020).

The metacognitive process between individuals in solving problems for every subject specifically in Mathematical problems is different, and these differences could be investigated based on their cognitive styles. One of the problems found in Mathematics is Calculus. This subject, particularly multivariable calculus, is one of the essential parts of the mathematics course for undergraduate students because it is essential in advanced mathematics and its applications (Kashefi, Ismail, \& Yusof, 2012). Further, it is considered the most difficult course and various problems experienced by students have been identified in multivariable calculus course (Kashefi, et al., 2012). Some of these difficulties are to understand the concepts and their relationship, coordinate procedures and manipulate concepts, have poor problem-solving skills, cannot select and use appropriate mathematical representations, cannot determine mathematical models of contextual problems, absorb new complex ideas in limited time, students' beliefs, and their learning styles. These problems possibly affect the subject content of multivariable calculus course, one of them is extreme value. This is the application of partial derivative that consist of two types; conditional and unconditional extreme value. Conditional extreme value can be solved by three methods of explicit, implicit, and Lagrange methods.

Indeed, the understanding of multivariable functions is a fundamental aspect for undergraduate students in numerous areas; however, students get difficulties studying the subject (Kashefi, et al., 2012). Moreover, they recommend the significance of utilizing computer-based instruments for developing students' mathematical thinking to overcome their impediments in multivariable calculus. It supports nowaday's condition that learning must be conducted in an online scheme. 
Based on the explanation above, metacognition is an essential factor that affects students' problem-solving activities, especially in mathematics. Studies from Faradiba et al., (2019); Murni et al., (2013); Wilson \& Conyers, (2016); Nizlel et al., (2016), and many more are discussing metacognition in problem-solving, including metacognitive failure to react to red flag situations. More specifically, a cognitive style is recognized to be critical in problem-solving (Mefoh et al., 2017), including multivariable calculus courses. Although the cognitive style is a factor that affects students' thinking processes (Mefoh et al., 2017), no research reveals the metacognitive process, especially the form of metacognitive failure in terms of cognitive style. Research related to metacognitive is also still rarely done in online learning. Therefore, this study investigates the metacognitive failure on mathematics errors when solving problems, especially in terms of cognitive style experienced by pre-service teachers in online learning during the pandemic era. Realizing the nature of mathematics errors based on metacognitive failure, teachers can use appropriate strategies to help students correct their errors.

\section{METHODS}

This research used a qualitative approach with a case study design. The researchers ensured that students have passed the partial derivative theory in advanced calculus courses in the online schema. These considerations are essential to ensure that the prospective subjects have sufficient knowledge to solve the mathematical problems, and this study was conducted both in synchronous or asynchronous learning systems. At first, the learning was held asynchronously through the Learning Management System (LMS). In this scenario, one of the researchers as lecturer used the LMS to submit modules and videos that discuss the subject material. The lecturer also provided a discussion forum in a written chat in the LMS where students could discuss things with one another if they did not understand the content. Besides, the lecturer, as facilitator also control the discussion forum. In the following, the learning process was continued with synchronous learning via a Zoom meeting to discuss unsolved problems. Using synchronous learning, the lecturer provided reinforcement and clarification if students have questions about the covered content. After that, the lecturer gave the mathematical problem to see the students' metacognitive process and to identify their possible metacognitive failure While, solving this mathematical problem, they were asked to turn on the camera so that the lecturer could control, capture all the gestures as essential things that students do while finishing the task, and ensure they do the assignments independently. The mathematical problems used in this study were adapted from Stewart (2005) and presented in Figure 1.

Find the points on the sphere $x^{2}+y^{2}+z^{2}=4$ that are closest to and farthest from the point $(3,1,-1)$

Figure 1. Original problem from Stewart (2005)

The problem from Figure 1 shows that the equation formed a sphere, which makes students do not need further analysis. Therefore, in this study, the information was eliminated so that the students should analyze the equation before solving the problem as shown in Figure 2. It is categorized as a conditional extreme value problem.

Find the points on the $x^{2}+y^{2}+z^{2}=4$ that are closest to and farthest from the point $(3,1,-1)$

Figure 2. Modified problem

The subjects were then instructed to solve the problem on a piece of paper via synchronous learning and requested to scan and upload final answers to a Google Form. Next, the researchers analyzed the students' work. Having been tested for the mathematical problem, to group them into field-dependent and field-independent (students' cognitive styles), the students were required to join the Group Embedded Figures Test (GEFT) which was comprised to seven practice items and two sets of nine items translated in Bahasa. Within 11 minutes, the participants were asked to arrange 18 shapes from basic geometric shapes to more complex ones. The GEFT scores range from 0 exceedingly FD to 18 
exceedingly FI. This implies that the scores $(x)$ for FD range from $0 \leq x<11$; meanwhile FI's scores start from $11 \leq x \leq 18$ (Nosratinia \& Adibifar, 2014). Out of 29 participants, 2 students were selected based on their unique answers on mathematical problems and their similar mathematical abilities. The different ways of solving problems indicate that they have diverse cognitive styles. In addition, the two subjects also have good communication skills and are willing to be the subjects as they would be further interviewed. This interview was to identify the nature of mathematical error based on metacognitive failure in the terms of subjects 'cognitive style.

\section{RESULTS AND DISCUSSION}

Results

Presented in the preceding section, there were two types of tests: mathematical problem-solving test and the GEFT. Among 29 participants, there were two groups of FD (13 students) and 16 students for FI. To get more depth exploration, two students were selected from each group. The followings are the results from the two subjects on mathematical problem-solving (Figures 3-7) and the interview results that informed the students' metacognitive failure and errors.

Figures 3-5 present the result from S1, a field-independent student, who solved the problem with an explicit method. S1 also gave unique signs to parts that are considered to be necessary. However, S1 was not careful enough to pay attention to the sign and made a mistake because S1 worked on and produced the wrong answers. More specifically, Figure 3 shows that $\mathrm{S} 1$ has determined the domain for its critical point and has given a unique sign. In opposite, Figure 4 presents that $\mathrm{S} 1$ directly determines the critical point without considering the domain so that the final answer is wrong. Meanwhile, Figure 5 shows the student did incorrect counting.

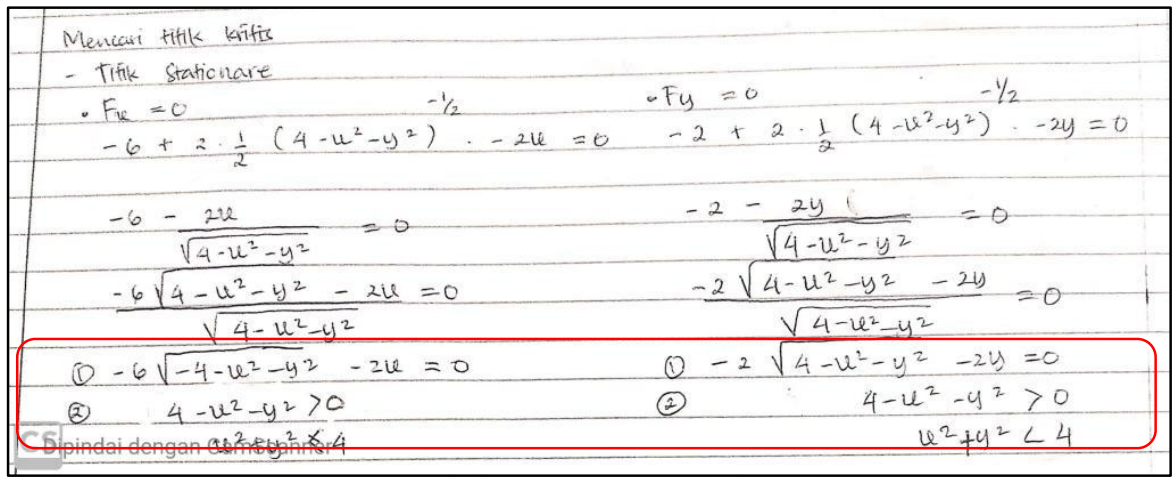

Figure 3. S1 determining the domain of critical points

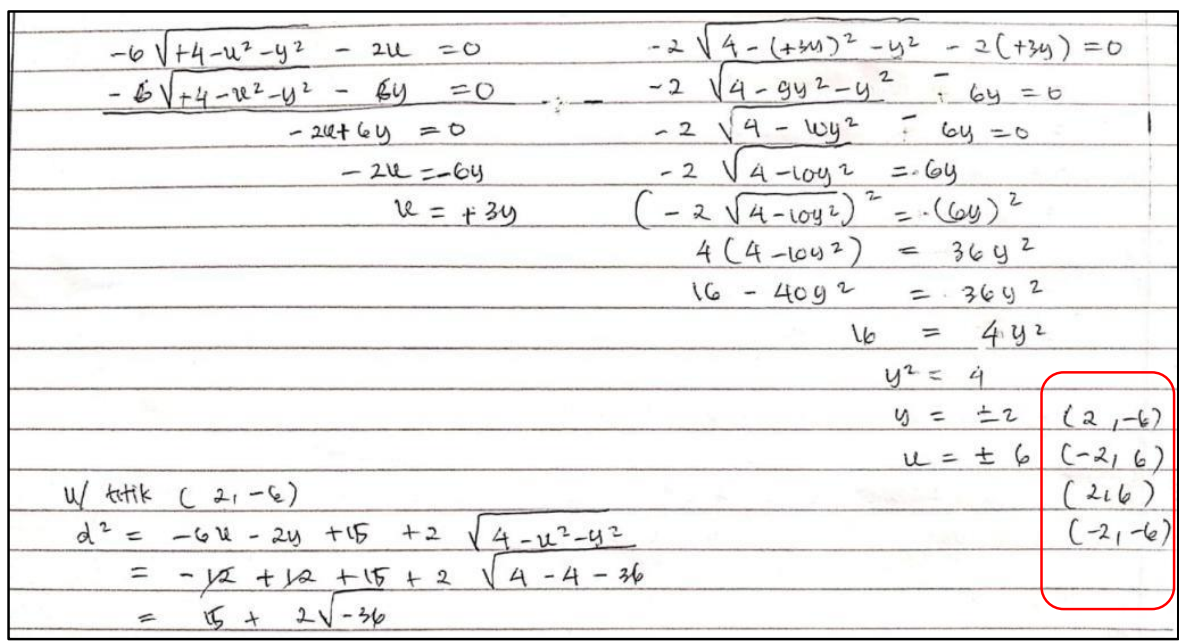

Figure 4. S1 makes a mistake in determining critical points 


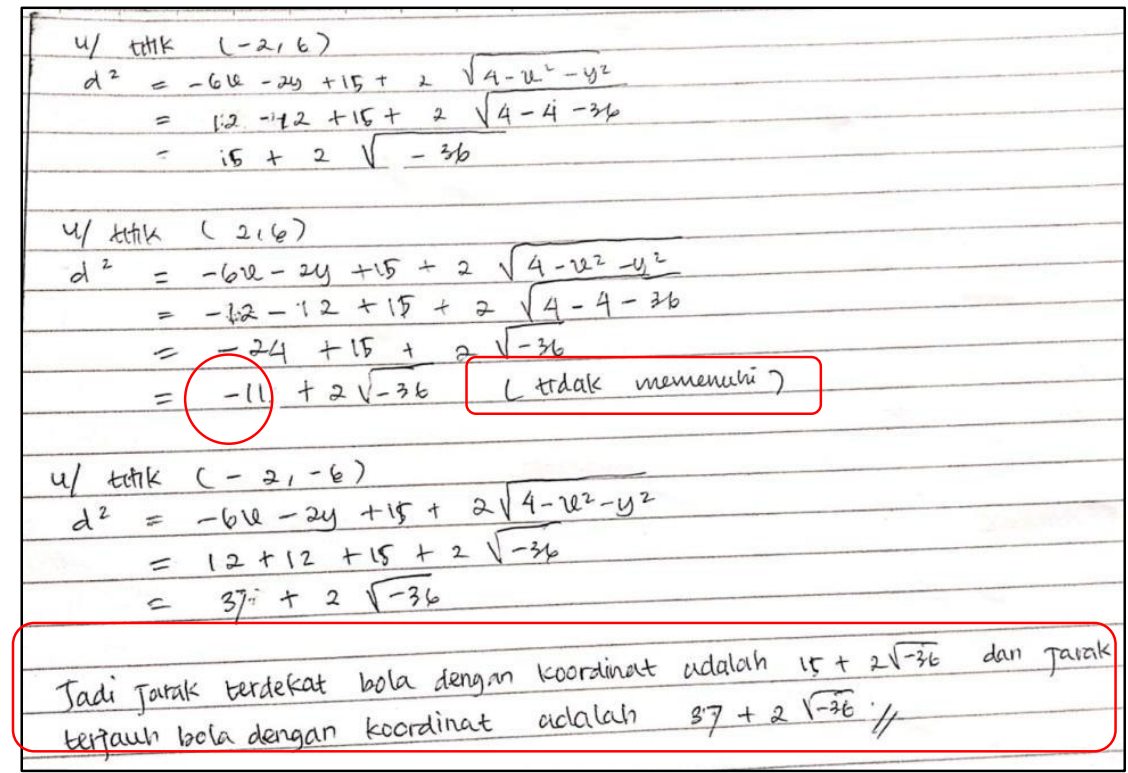

Figure 5. S1 gets the wrong answer

For further data, S1 was interviewed to get more complete information related to her metacognitive process and the errors as presented in the following transcript. From the interview, it could be seen that S1 initially did not realize her mistake; after the interview process, S1 realized her mistake as shown in Figure 5.

\section{S1 Transcript:}

$R$ : Are you sure about your final answer?

S1: I think so, Ma'am

$R$ : Have you checked your answers?

S1: Not yet, Ma'am, because it seems correct, the answer has been found. I did not meet any difficulties.

R: Please explain; why is this not satisfying while the others meet?

S1: Yes, distance is impossible because (-11) negative, Ma'am.

$R$ : Oh, look at the numbers at the root? Are negative numbers in the root are allowed to distance?

S1: Oh, yes, ma'am. My fault

$R:$ Where do errors start?

S1: (recheck the answer and find the error) This Ma'am (pointing at Figures 1 and 2), I ignore the domain.

$R$ : Try to correct it first

S1: (try to do by paying attention to the domain) ... I cannot find the critical points.

$R$ : Why is that? Is there something wrong? Please recheck.

S1: (try checking again) ... Looks like the explicit strategy is not suitable, ma'am. Must use other strategies

The next data indicate the results from S2, field-dependent student. Figure 6 shows S2's understanding of the problem, while Figure 7 indicates his answer when he solved the problem with extreme value finding procedures. However, he did not reach the final result.

$x^{2}+y^{2}+z^{2}=4$
dari titik koordinat $(3,1,-1)$
nilai minimum $=\ldots$ ?
nílai maksimum $=\ldots$ ?

Figure 6. S2 understanding 


\begin{tabular}{|c|c|}
\hline$v^{2}+y^{2}+$ & $=0$ \\
\hline$=2$ & $D=f_{x x} \cdot f_{y y}-f_{x y^{2}}$ \\
\hline$f x y=0$ & $=2 \cdot 2-(0)^{2}$ \\
\hline$f y y=2$ & $=4>0$ minimum lokal \\
\hline
\end{tabular}

Figure 7. The answer of S2

Similar to S1, S2 was also interviewed to explore his metacognitive process and errors.

The transcript below shows that S2 incorrectly selected the solving problem strategies that lead to his error.

\section{S2 Transcript:}

$R$ (researcher): When you read the question, what first crossed in your mind?

S2: This problem is related to the maximum-minimum value, Ma'am. (awareness)

$R$ : Do you think you can do it or not?

S2: I think so.

$R$ : Why did you stop?

S2: I got stuck, ma'am

$R:$ Why is it stuck?

S2: I was asked for the maximum and minimum values, but I only found the minimum value when applying them in the formula. I am confused about where the maximum value will be obtained.

$R$ : Did not you do further analysis?

S2: I have tried to correct my answer again, but I feel it is correct, ma'am.

$R$ : Are you confident in your answer?

S2: Not, ma'am, because I cannot find the results.

$R$ : Didn't you try to analyze the problem again?

S2: No, ma'am, it is clear about finding the maximum and minimum values

$R$ : Did you try another method?

S2: Is there any other method Ma'am? I do not think so.

$P:$ Then, why not meet the correct answer?

S2: I also do not know Ma'am; I will try to discuss it later with my friend

\section{Discussion}

Having been given the mathematical problems and the GEFT, it was found out that there are two students selected as the subjects to be categorized as FI and FD and be further interviewed. The student with the Field Independence (FI) cognitive style is represented by Subject 1 (S1). This subject has experienced metacognitive awareness in identifying the types of questions as in line with Magiera \& Zawojewski (2011). Here, S1 determined the questions by looking at the general form of the function. S1 showed the characteristics of FI expressed by Oh \& Lim (2005) and (Ling \& Salvendy, 2009) that individual FI tends to always involve analysis in mastering tasks.

Furthermore, the finding also confirms Magiera \& Zawojewski (2011) that S1 experienced metacognitive evaluation in considering the most appropriate strategy and metacognitive regulation to select the best strategy based on her abilities. In this case, S1 chose to use the explicit method and completed it according to the correct procedural steps. At the beginning of working, S1 did the job precisely based on the steps. S1 also gave unique signs to the parts that are considered critical where S1 is seen giving numbers which are then circled. This implies that S1 has the characteristics of being FI that is paying attention to details (Oh \& Lim, 2005; Ling \& Salvendy, 2009).

However, S1 was less careful in paying attention to details that have been marked by herself, and $\mathrm{S} 1$ failed to determine the critical point. As she ignored the domain, it resulted in the wrong final answer. S1 did not realize her mistake so she did not stop or was not aware of the red flag which leads to metacognitive failure. This condition supports Faradiba et al. (2019) who said that the metacognitive 
process does not always run smoothly without obstacles; if there is a failure in the metacognition process, it can lead to metacognitive failure or known as a metacognitive failure. This study reveals that metacognitive failures in $\mathrm{S} 1$ can be categorized as metacognitive blindness because $\mathrm{S} 1$ did not realize the red flag. The S1 condition indicates that her explicit method is not always applicable to every problem. Some questions are easier to work out explicitly, and some are not. S1 does not consider this in the process of determining strategy. Therefore, it can be concluded that S1 has strategic errors as stated by Luo, (2013). Finally, the errors S1 made could be realized once she was interviewed.

Student with Field Dependence (FD) cognitive style is represented by Subject 2 (S2). Similar to $\mathrm{S} 1, \mathrm{~S} 2$ has also carried out a metacognitive awareness process to identify questions and recognize their knowledge, as found by Magiera \& Zawojewski (2011) even though the results of S2 identification are not entirely accurate. S2 only considered a global problem related to the maximum-minimum (extreme problem), and $\mathrm{S} 2$ did not realize and conduct further analysis that the problem also indicates conditional extreme. This situation implies that S2 meets the FD characteristics based on Oh \& Lim (2005). S2 did not do metacognitive evaluation to select the appropriate strategies for solving the problem as he just knew one type of strategy, namely extreme problem. The error made as shown in Figure 7 indicate that S2 immediately looked for the partial derivative of the function explicitly even though the function is still implicit. In contrast, it must be converted to explicit before deciding the partial derivative. In this case, S2 realized that he made a "red flag" where he stopped working and re-evaluated the answer.

Based on the interview result, it was deeply found that S2 could not find the error's location even though he experienced the red flag and the mathematical errors. Further information says that $\mathrm{S} 2$ thought that his strategies were already correct that unfortunately, it was not. The fact that he could not understand why he could not find the correct answer for the error that is included in metacognitive failure. However, no type of this metacognitive failure fits the case explained by Goos (2002) which was presented in Figure 8. The subject in this study shows that he (S2) did not sustain the metacognitive blindness because he realized the red flag. S2 did not sustain a metacognitive mirage because he had the wrong answer. Also, S2 did not have metacognitive vandalism because S2 did not do anything that messed up the problem or the answer. S2 did not make any response to the red flag. Indeed, this study reveals that $\mathrm{S} 2$ sustains the metacognitive failure because there is something wrong as he did not realize his mistake as can be seen from the Figure 8 (Goos 2002).

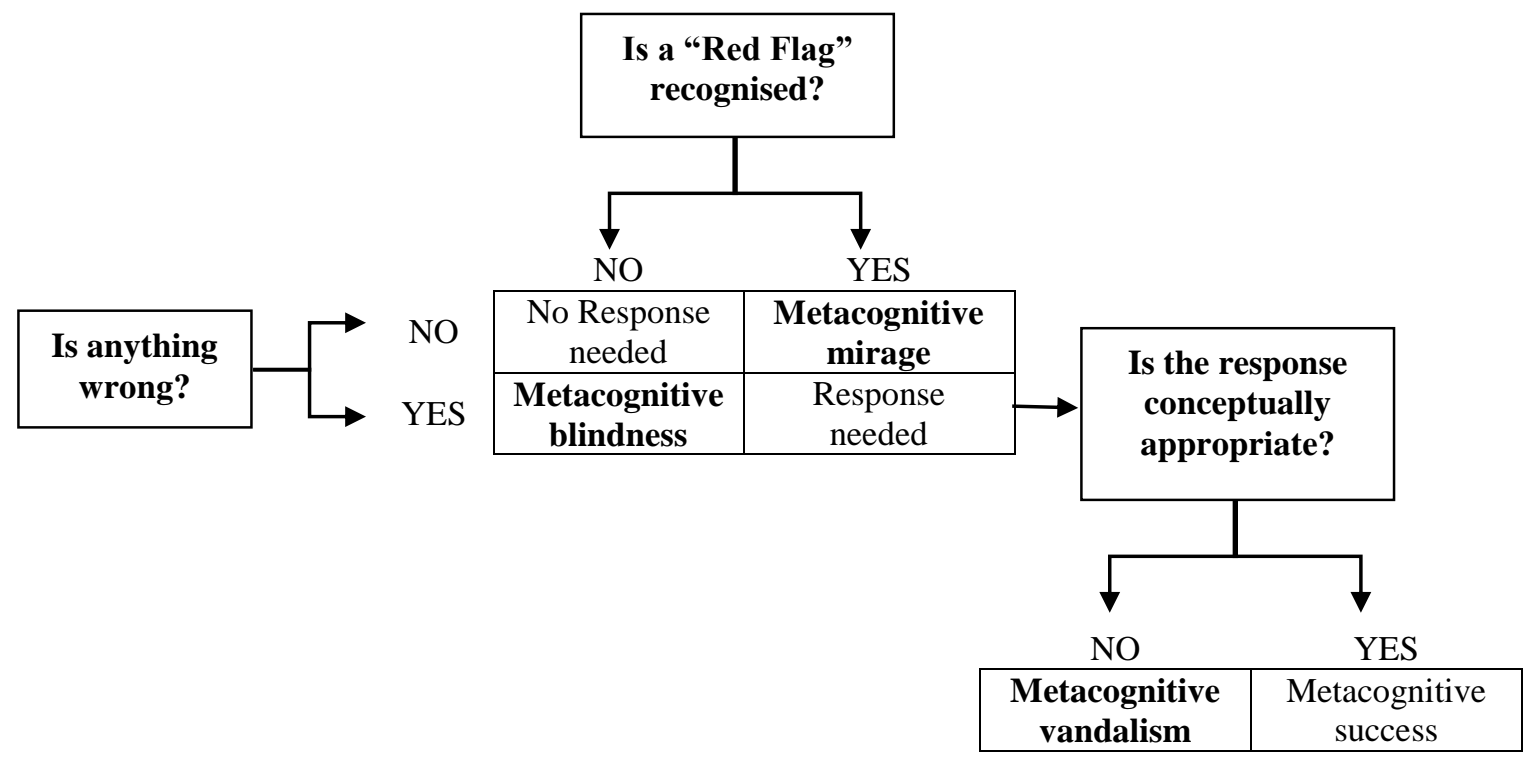

Figure 8. The metacognitive success and failure scenario

At the end of the interview, it was found out that S2, as FD student, needs to discuss with his friend (someone else) to help him overcome the problem. This condition is similar to $\mathrm{Oh} \& \mathrm{Lim}$ (2005); Ling \& Salvendy (2009); Riding \& Rayner (2020) who state that FD individuals are more social, easily influenced by the environment or context, and responsive to others. Son et al., (2020) also 
argues that $\mathrm{S} 2$ relies on outside influences, in this case, in the form of help from friends when solving a problem. So, it can be said that S2, as FD individuals, tend to look at things globally and need help from others when facing problems. At the beginning stage of the metacognitive process, S2 had conducted metacognitive awareness in identifying questions and thinking about the knowledge possessed even though the identification results were still not quite right. S2 was aware of an error (red flag) but did not respond to the red flag. Therefore, the researcher categorizes a new condition of metacognitive failure (MF), namely Metacognitive Stagnation, which occurs when the subject is aware of a red flag but does not respond to the red flag. It completes the Metacognitive Success and Failure Scenario of (Goos 2002) and as presented in Figure 9.

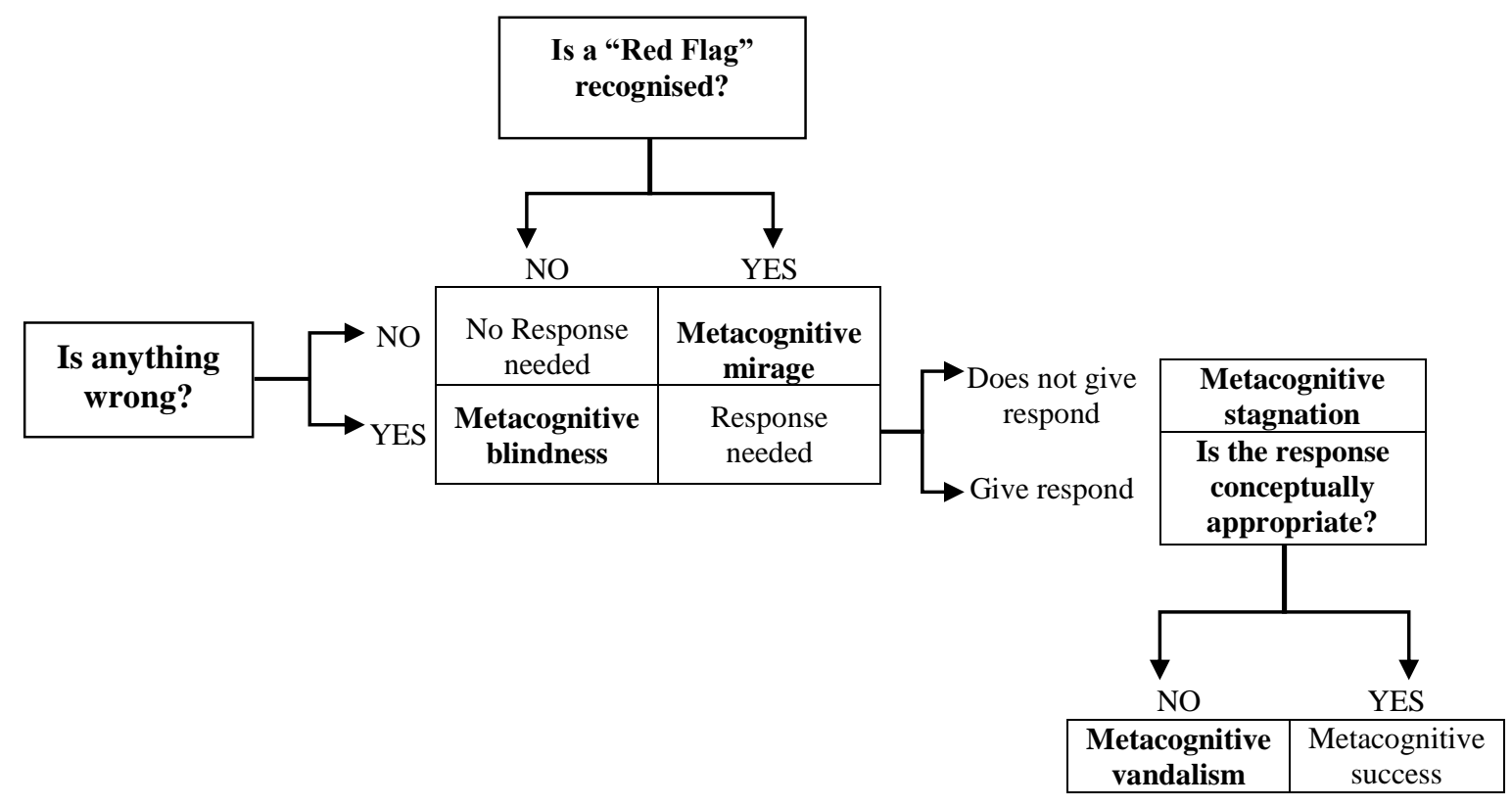

Figure 9. The new metacognitive success and failure scenario

\section{CONCLUSION}

This study reveals that $\mathrm{S} 1$ as FI has different problem-solving processes compared to S2 as FD student. S1 as FI shows the characteristics of FI in terms of involving analysis. S1 has already conducted a process of metacognitive awareness, evaluating, and regulating to mind-map the problems, determine the strategies that can be used and steps to work based on the selected strategies. However, in the process, S1 made an error in determining strategy (strategic errors). S1 did not realize the error, so it can be said that $\mathrm{S} 1$ is unaware of the red flag and is categorized as experiencing metacognitive blindness.

S2, as FD, viewed the problem globally and did not involve the analysis process. FD already involved a metacognitive process, namely metacognitive awareness, in identifying questions and thinking about the knowledge possessed even though the identification results were incorrect. S2 had an error in identifying the related concept (mathematical error), and he was aware of the error and realized the red flag. However, this condition does not meet any type of metacognitive failure where S2 was aware of an error (red flag) but did not respond to the red flag. Therefore, in this particular condition of online learning, the researchers categorize a new condition of MF, namely Metacognitive Stagnation.

\section{REFERENCES}

Abdullah, A. H., Mokhtar, M., Halim, N. D. A., Ali, D. F., Tahir, L. M., \& Kohar, U. H. A. (2017). Mathematics teachers' level of knowledge and practice on the implementation of higher-order thinking skills (HOTS). Eurasia Journal of Mathematics, Science and Technology Education, 13(1), 3-17. https://doi.org/10.12973/eurasia.2017.00601a

Amin, I., \& Sukestiyarno, Y. L. (2015). Analysis metacognitive skills on learning mathematics in high school. International Journal of Education and Research, 3(3), 213-222. 
http://www.ijern.com/journal/2015/March-2015/18.pdf

Faradiba, S. S., Sa'dijah, C., Parta, I. N., \& Rahardjo, S. (2019). Looking without seeing: The role of metacognitive blindness of student with high math anxiety. International Journal of Cognitive Research in Science, Engineering and Education, 7(2), 53-65. https://doi.org/10.5937/IJCRSEE1902053F

Gagatsis, A., \& Kyriakides, L. (2000). Teachers' attitudes towards their pupils' mathematical errors. Educational Research and Evaluation, 6(1), 24-58. https://doi.org/10.1076/13803611(200003)6:1;1-i;ft024

Goos, M. (2002). Understanding metacognitive failure. Journal of Mathematical Behavior, 21(3), $283-$ 302. https://doi.org/10.1016/S0732-3123(02)00130-X

Hidayah, I. N., Sa'dijah, C., Subanji, \& Sudirman. (2021). The students' cognitive engagement in online mathematics learning in the pandemic Covid-19 era. AIP Conference Proceedings, 2330(March). https:/doi.org/10.1063/5.0043567

Kashefi, H., Ismail, Z., \& Yusof, Y. M. (2012). Overcoming students obstacles in multivariable calculus through blended learning: A mathematical thinking approach. Procedia - Social and Behavioral Sciences, 56(Ictlhe), 579-586. https://doi.org/10.1016/j.sbspro.2012.09.691

Kashefi, H., Ismail, Z., Yusof, Y. M., \& Rahman, R. A. (2012). Fostering mathematical thinking in the learning of multivariable calculus through computer-based tools. Procedia - Social and Behavioral Sciences, 46, 5534-5540. https://doi.org/10.1016/j.sbspro.2012.06.471

Kozhevnikov, M., Evans, C., \& Kosslyn, S. M. (2014). Cognitive style as environmentally sensitive individual differences in cognition: A modern synthesis and applications in education, business, and management. Psychological Science in the Public Interest, Supplement, 15(1), 3-33. https://doi.org/10.1177/1529100614525555

Lester, F. K. (2013). Thoughts about research on mathematical problem-solving instruction. The Mathematics Enthusiast, 10(1), 245-278. https://doi.org/10.54870/1551-3440.1267

Li, S., Lajoie, S. P., Zheng, J., Wu, H., \& Cheng, H. (2021). Automated detection of cognitive engagement to inform the art of staying engaged in problem-solving. Computers and Education, 163, 104114. https://doi.org/10.1016/j.compedu.2020.104114

Ling, C., \& Salvendy, G. (2009). Effect of evaluators' cognitive style on heuristic evaluation: Field dependent and field independent evaluators. International Journal of Human Computer Studies, 67(4), 382-393. https://doi.org/10.1016/j.ijhcs.2008.11.002

Luo, Z. (2013). A framework mathematics as for examining knowledge teacher analysis used. Knowing and Using Mathematics in Teaching, 29(3), 22-25. https://www.jstor.org/stable/25594562

Magiera, M. T., \& Zawojewski, J. S. (2011). Characterizations of social-based and self-based contexts associated with students'awareness, evaluation, and regulation of their thinking during small-group mathematical modeling. Journal for Research in Mathematics Education, 42(5), 486-520. https://doi.org/10.5951/jresematheduc.42.5.0486

Mefoh, P. C., Nwoke, M. B., Chukwuorji, J. B. C., \& Chijioke, A. O. (2017). Effect of cognitive style and gender on adolescents' problem solving ability. Thinking Skills and Creativity, 25, 47-52. https://doi.org/10.1016/j.tsc.2017.03.002

Murni, A., Sabandar, J., Kusumah, Y. S., \& Kartasamita, B. G. (2013). The enhancement of junior high school student's skill-based metacognitive learning. Journal on Mathematics Education, 4(2), 194-203. https://doi.org/10.22342/jme.4.2.554.194-203

Nizlel, H., Subanji, Toto, N., Susiswo, Akbar, S., \& Swasono, R. (2016). University students metacognitive failures in mathematical proving investigated based on the framework of assimilation and accommodation. Educational Research and Reviews, 11(12), 1119-1128. https://doi.org/10.5897/err2016.2721 
Nosratinia, M., \& Adibifar, S. (2014). The effect of teaching metacognitive strategies on field-dependent and independent learners' writing. Procedia - Social and Behavioral Sciences, 98, 1390-1399. https://doi.org/10.1016/j.sbspro.2014.03.557

Oh, E., \& Lim, D. (2005). Cross relationships between cognitive styles and learner variables in online learning environment. Journal of Interactive Online Learning, 4(1), 53-66. https://eric.ed.gov/?id=EJ1066791

Palmer, E. C., David, A. S., \& Fleming, S. M. (2014). Effects of age on metacognitive efficiency. Consciousness and Cognition, 28(1), 151-160. https://doi.org/10.1016/j.concog.2014.06.007

Patricia Aguilera-Hermida, A. (2020). College students' use and acceptance of emergency online learning due to COVID-19. International Journal of Educational Research Open, 1, 100011. https://doi.org/10.1016/j.ijedro.2020.100011

Rahiem, M. D. H. (2021). Remaining motivated despite the limitations: University students' learning propensity during the COVID-19 pandemic. Children and Youth Services Review, 120, 105802. https://doi.org/10.1016/j.childyouth.2020.105802

Richardson, J. C., \& Newby, T. (2006). The role of students' cognitive engagement in online learning. International Journal of Phytoremediation, 21(1), 23-37. https://doi.org/10.1207/s15389286ajde2001_3

Riding, R., \& Rayner, S. (2020). Cognitive style and learning. Cognitive Styles and Learning Strategies, March, 145-168. https://doi.org/10.4324/9781315068015-13

Shekhar, M., \& Rahnev, D. (2021). Sources of metacognitive inefficiency. Trends in Cognitive Sciences, 25(1), 12-23. https://doi.org/10.1016/j.tics.2020.10.007

Shukor, N. A., Tasir, Z., Van der Meijden, H., \& Harun, J. (2014). A predictive model to evaluate students' cognitive engagement in online learning. Procedia - Social and Behavioral Sciences, 116(2006), 4844-4853. https://doi.org/10.1016/j.sbspro.2014.01.1036

Son, A. L., Darhim, \& Fatimah, S. (2020). Students' mathematical problem-solving ability based on teaching models intervention and cognitive style. Journal on Mathematics Education, 11(2), 209222. https://doi.org/10.22342/jme.11.2.10744.209-222

Stewart, J. (2005). Multivariable calculus: Concepts and contexts. Belmont CA: Thomson Brooks/Cole.

Vula, E., Avdyli, R., Berisha, V., Saqipi, B., \& Elezi, S. (2017). The impact of metacognitive strategies and self-regulating processes of solving math word problems. International Electronic Journal of Elementary Education, 10(1), 49-59. https://doi.org/10.26822/iejee.2017131886

Wilson, D., \& Conyers, M. (2016). Teaching students to drive their brains: Metacognitive strategies, activities, and lesson ideas. Alexandria, VA: ASCD.

Zheng, F., Khan, N. A., \& Hussain, S. (2020). The COVID 19 pandemic and digital higher education: Exploring the impact of proactive personality on social capital through internet self-efficacy and online interaction quality. Children and Youth Services Review, 119, 105694. https://doi.org/10.1016/j.childyouth.2020.105694 